\title{
Correction to: Expressing Experiences of Coworking Spaces: Insights from Social Media
}

\author{
Tadashi Uda
}

\section{Correction to:}

Chapter 10 in: M. Orel et al. (eds.), The Flexible Workplace, Human Resource Management, https://doi.org/10.1007/978-3-030-62167-4_10

Owing to an oversight, the ruled lines (right side: the part of Behaviors) of Table 2 in Chapter 10 were missing. The same have now been corrected in the chapter. 
Table 2 Data structure

\begin{tabular}{l|l|l}
\hline First-order codes & Second-order themes & Aggregate dimensions \\
\cline { 1 - 1 } Facility & Services & Space \\
\cline { 1 - 1 } Systems & & \\
\cline { 1 - 1 } Environments & & \\
\cline { 1 - 1 } Other users & & \\
\cline { 1 - 1 } Socation & & \\
\cline { 1 - 1 } Provider & & \\
\cline { 1 - 1 } Concept & & \\
\cline { 1 - 1 } Implementing & & \\
\cline { 1 - 1 } Productivity & & \\
\cline { 1 - 1 } Attitudes & & \\
\cline { 1 - 1 } Modes & & \\
\cline { 1 - 1 } Performance & & \\
\cline { 1 - 1 } Descriptions & & \\
\cline { 1 - 1 } Frequency & & \\
\cline { 1 - 1 } Aim & & \\
\cline { 1 - 1 } Feelings & & \\
\cline { 1 - 1 } Activities & & \\
\cline { 1 - 1 } Situations & & \\
\cline { 1 - 1 } Places & & \\
\cline { 1 - 1 } People & & \\
\cline { 1 - 1 } Impressions & & \\
\cline { 1 - 1 } Outcoments & & \\
\hline Purpose & & \\
\hline
\end{tabular}

